\title{
The Prevalence of Hypertension, Ischaemic Heart Disease and Diabetes in Traumatic Spinal Cord Injured Patients and Amputees
}

\author{
M. Yekutiel, PhD, M. E. Brooks, MD, A. Ohry, MD, J. Yarom, MD, R. \\ Carel, MD \\ Rehabilitation Center, Chaim Sheba Medical Center, Sackler School of Medicine, \\ Tel Aviv University, Tel Hashomer 52621, Israel.
}

\begin{abstract}
Summary
The clinical impression that spinal cord injured and traumatic lower limb amputees are more prone to develop degenerative diseases was investigated by comparing the prevalance of hypertension, ischaemic heart disease, and diabetes mellitus in these two patient groups with the prevalence of these diseases among a group of healthy agematched controls. Seventy seven spinal cord injured patients and 53 amputees fulfilled the criteria for inclusion in this study. Our results show a significant increased incidence of hypertension and ischaemic heart disease among those with spinal cord injuries compared with their controls; and among the amputees, a significant increased incidence of ischaemic heart disease and of diabetes mellitus.
\end{abstract}

Key words: Spinal cord injury; Amputees; Hypertension; Ischaemic heart disease; Diabetes mellitus.

Despite the ever improving statistics of life expectancy in the spinal cord injured patient (SCIP), there is still a significant shortening of life span after the injury (De Vivo et al., 1980; Geisler et al., 1983; Nyquist and Bors, 1967). Ryder (1979) showed a significant increase in mortality during a 30-year follow-up of World War II soldiers who underwent amputation as a result of war injuries. Bakalin (1969), in a study of 4788 Finnish World War II amputees, found no difference in mortality rates as compared to the general population. However, examination of causes of death showed that these amputees had a $63.1^{\circ}{ }_{0}$ greater death rate from degenerative cardiac and vascular diseases. To test the clinical impression that SCIP and traumatic lower limb amputee patients (TLLAP) are more prone to develop degenerative diseases, we investigated the prevalence of hypertension, ischaemic heart disease, and diabetes mellitus in these two groups of traumatic injuries, and compared it to the incidence among age-matched controls.

Correspondence to: Dr. Moshe Elyakim Brooks MD, Department of Neurological Rehabilitation, Chaim Sheba Medical Center, Tel Hashomer, 52621, Israel. 


\section{Methods}

Hospital records of 247 SCIP and 81 TLLAP were examined for the following criteria for inclusion in the study:

1. Male.

2. Injured before 1974 .

3. Below age 30 at the time of injury.

4. Sole etiology of cord injury or of amputation; trauma.

5. No illness or disease at the time of trauma.

6. Availiblity of adequate documentation and follow-up.

The records of these two groups were studies for:

1. The presence of hypertension, ischaemic heart disease, and diabetes mellitus.

2. The relationship between the presence of these diseases and the level of the spinal cord injury, the presence or absence of spasticity, and the completeness of the spinal cord injury.

3. The relationship between the general level of physical activity (walking, working, participation in sports) and the presence of these three diseases in the two patient groups.

4. Comparison of below knee and above knee amputees and the healthy control group.

The age-distribution of both patient groups reflects the fact that they represent men wounded (for the most part in their early 20s) in the wars of 1948-1949, 1956, 1967, and 1973. Great care was therefore taken to use an age-matched control population. The control group was extracted from a large (approximately 50000 ) computerised database of one multiphasic screening centre where an apparently healthy population is screened, mostly in periodical checkups or pre-employment examinations. In previous studies, it was shown that the screened population represents well the employed population of the country (Carel and Lesham, 1980; Carel et al., 1984; Tartakovski, 1983). Using a matching algorithm, sex, year of birth and date of last examination within 2 years of that of the patient, three control subjects from the same birth year were taken for each patient.

The uniform comprehensive health profile (Carel and Lesham, 1980) available on each examinee in the screening process of these presumably well men, allowed for the extraction of information regarding previous diagnoses, blood pressure measurement, electrocardiogram, blood chemistry and physical examination. Blood pressure measurements considered were based on several repeated measurements in one encounter, out of which the one with the lowest diastolic pressure was taken as the representative casual measure. For both patients and controls, hypertension was defined as measurements above 140 $\mathrm{mm}$ mercury systolic and/or $95 \mathrm{~mm}$ mercury diastolic. Ischaemic heart disease was diagnosed by conventional ECG criteria or by history of myocardial infarction or angina pectoris; the electrocardiogram being done in the conventional 12-lead-scalar recording with all results being reviewed by certified cardiologists using the same standardised codes for interpretation for all the patients and controls. Diagnosis of diabetes mellitus was based on the history of treatment or of elevated fasting blood glucose of $140 \mathrm{mg}^{\%}$ or more. 
In the statistical analysis, the chi-square test was used to test the significance of the difference between the proportions of affected and non-affected in-patient and control groups, the control group comprising in every case three agematched controls for each patient.

\section{Results}

The study population comprised 77 spinal cord injured patients (SCIP) and 53 traumatic lower limb amputee patients (TLLAP) who conformed with the criteria for inclusion. Multiple trauma accounted for most of the exclusions. The SCIP ranged in age from 27 to 62 years, with a mean of 40.4 years, and the TLLAP ranged from 41 to 72 years with a mean of $57 \cdot 2$ years.

Table I shows that approximately $34^{\circ}{ }_{\circ}^{\circ}$ of the SCIP suffer from hypertension, ischemic heart disease or diabetes mellitus as compared to $18.6 \%$ of the controls, the difference being statistically significant $(\mathrm{p}<0.01)$. The SCIP show a significant excess of both hypertension and ischaemic heart disease. The number of diabetics is small and the excess compared with the controls is not statistically significant.

The TLLAP group show a significant excess of ischaemic heart disease and diabetes mellitus but not of hypertension as compared to the controls. In none of the diseases studied is there any relationship to the level of amputation (Table I). A study of disease prevalence by age shows that where there is a significant total excess, each age group shows figures in excess of those expected from the prevalence rates among contols (data not presented here).

The distribution of hypertension and ischaemic heart disease was studied in relation to level of cord lesion, completeness of lesion, and presence or absence of spasticity. None of these variables showed any statistical relationship with the presence of any of the three diseases. Also no relationship was found in the SCIP group between the three degenerative diseases and the presence or absence of pressure sores, chronic urinary tract infection, burns, respiratory infections and embolic phenomena of all sources. Approximately $60 \%$ of all patients suffered from one or more of these complications.

Patient physical activity as determined by work, ambulation and sports participation is shown in Table II. The relatively high prevalence of hypertension and ischemic heart disease among the non-ambulating patients and among those not participating in sport is suggestive, but the numbers are small and do not reach statistical significance.

\section{Discussion}

Earlier research has shown that one of the major causes of death in the SCIP group is renal failure with a large percentage of these patients having postmortem renal changes consistent with hypertension (Talbot, 1966; Tribe and Silver, 1963). However, other studies (Moeller, 1962; Nyquist and Bors, 1967; Saito, 1964) have shown that hypertension is not an accompanying feature of spinal cord injury; rather, it is a reflection of the severity of the progressive renal pathology. In our group of patients, investigation of renal function via pyelography and creatinine clearance showed no recognisable renal pathology. 
Table I Prevalence of degenerative diseases in the SCIP and the TLLAP and in age-matched controls

\begin{tabular}{|c|c|c|c|c|c|}
\hline & $\begin{array}{c}\text { No. } \\
\left({ }^{\circ} \text { o prevelance }\right)\end{array}$ & Hypertension & $\begin{array}{c}\text { Ischaemic } \\
\text { heart } \\
\text { disease }\end{array}$ & $\begin{array}{l}\text { Diabetes } \\
\text { Mellitus }\end{array}$ & $\begin{array}{l}\text { One or } \\
\text { more } \\
\text { diseases }\end{array}$ \\
\hline SCIP & 77 & $19(24 \cdot 7)^{\star \star}$ & $13(16.9)^{\star \star}$ & $4(5 \cdot 2)$ & $26(33 \cdot 8)^{\star}$ \\
\hline Controls & 231 & $24(10 \cdot 4)$ & $16(6 \cdot 9)$ & $7(3)$ & $43(18 \cdot 6)$ \\
\hline \multicolumn{6}{|l|}{ TLLAP } \\
\hline Above knee & 26 & $11(42 \cdot 3)$ & $6(23 \cdot 1)$ & $6(23 \cdot 1)$ & $16(61 \cdot 5)$ \\
\hline Below knee & 27 & $8(29 \cdot 6)$ & $11(40 \cdot 7)$ & $6(22 \cdot 2)$ & $17(63)$ \\
\hline Total & 53 & $19(35 \cdot 8)$ & $17(32 \cdot 1)^{\star}$ & $12(22 \cdot 6)^{\star}$ & $33(62 \cdot 3)$ \\
\hline Controls & 159 & $56(35 \cdot 2)$ & $29(18 \cdot 2)$ & $15(9 \cdot 4)$ & $76(47 \cdot 8)$ \\
\hline
\end{tabular}

Table II Activity level in SCIP: Relationship to the presence of degenerative disease

\begin{tabular}{lccr}
\hline & $\begin{array}{c}\text { Hypertension } \\
\text { No. }\left({ }_{0}^{\circ} \text { prevelance }\right)\end{array}$ & $\begin{array}{c}\text { Ischaemic heart disease } \\
\text { No. }\left({ }_{0}^{\circ} \text { prevalence }\right)\end{array}$ & Total \\
\hline Work & $13(26)$ & $8(16)$ & 50 \\
Non-work & $5(23)$ & $3(14)$ & 22 \\
Unknown & 1 & $1(8)$ & 5 \\
Ambulate & $1(8)$ & $10(17)$ & 13 \\
Non-ambulating & $17(29)$ & 2 & 59 \\
Unknown & 1 & $2(11)$ & 5 \\
Sports participation & $3(17)$ & $9(17)$ & 18 \\
No sports & $15(29)$ & 2 & 52 \\
Unknown & 1 & & 7 \\
\hline
\end{tabular}

If all the patients with ischaemic heart disease in the SCIP group also suffered from hypertension, then the etiology would be easy to explain. However, in $70^{\circ}{ }_{0}$ of the cases, each SCIP had only one disease entity. Thus, for both hypertension and ischaemic heart disease in the SCIP a reason or mechanism not intrinsically related to the cord injury must be found.

Gordon et al. (1977) and Gouldbourt and Medalie (1979) have shown that high density lipoprotein cholesterol (HDLC) has a significant preventative action in the development of ischaemic heart disease. Blackburn (1983) and Leon and Blackburn (1977) have shown that a lack of physical activity increases the risk of ischaemic heart disease as a result of the decreased levels of HDLC. La Porte et al. (1983) have shown that the level of HDLC is directly related to the level of physical activity. Heldenberg et al. (1981) and Vaziri et al. (1982) have shown that the level of HDLC is decreased in SCIP as compared to the normal population. The present study suggests that the SCIP is susceptible to an increased incidence of ischaemic heart disease as a result of his more sedentary existance. Our data support this hypothesis, with $17^{\circ}$ o of the SCIP having ischaemic heart disease as compared with an expected $7^{\circ}{ }_{0}$.

Concerning the TLLAP group, ischaemic heart disease and diabetes mellitus were present in significantly increased numbers as compared to a normal population. These results are compatable with the findings of Hrubec and Ryder (1980). Once again, this group shows no difference in personal habits, i.e. 
smoking, increased weight etc., from those of the general population. The only difference which can explain their predisposition to development of these degenerative diseases is the difference in activity level, with the amputees being much more sedentary. In both the SCIP and the TLLAP groups, the stress of the injury and the drastic change in life style, both psychological as well as physical, probably contribute to the development of these diseases.

\section{Acknowledgement}

This work was supported by a grant from the Ministry of Defense, Department of Rehabilitation, State of Israel.

\section{References}

BAKalim G 1969 Causes of death in a series of 4738 Finnish war amputees. Artificial Limb 13:27.

BLACKBURN H 1983 Physical activity and coronary heart disease: a brief update and population view, fournal of Cardiovascular Rehabilitation 3:101.

CAREL RS, LESHEM G 1980 Evaluation of the cost-effectiveness of an automated multiphasic Health Testing System. Preventive Medicine 10:789-797.

CAREL RS, Silverberg DS, MOR G 1984 Screening for hypertension in a working population. Public Health 98:327-332.

De Vivo M, Fine PR, MAetz HM, STORER SL 1980 Prevelence of spinal cord injury reestimation employing life table techniques. Archives of Neurology 37:707.

Geisler WO, Jousse AT, WyNNE-JoNEs M, BREIThOupt D 1983 Survival in traumatic spinal cord injury. Paraplegia 21:364.

Gordon T, CAStelli W, Hortland M et al. 1977 High density lipoprotein as a protective factor against coronary heart disease, the Framingham Study. American fournal of Medicine 62:707.

Gouldbourt U, Medalie JA 1979 High density lipoprotein cholesterol and the incidence of heart disease, Israeli ischemic heart disease study American fournal of Epidemiology 109:296.

Heldenberg D, Rubinstein A, Levtov D et al. 1981 Serum lipids and lipoprotein concentrations in young quadriplegic patients. Atheroscleosis 39:163.

Holzaman E, Gouldbourt U, Rosenthal T et al. 1983 Hypertension in middle-aged men. fournal of Medical Science 19:25.

HRUBec Z, RYDER RA 1980 Traumatic limb amputation and subsequent mortality from cardiovascular diseases and other causes. Fournal of Chronic Diseases 33:239.

La Porte RE, Brenes G, Dearwater S et al. 1983 High density lipoprotein-cholesterol across a spectrum of physical activity from quadriplegia to marathon running. Lancet i:1212.

LEON AS, BLACKBURN H 1977 The relationship of physical activity to coronary heart disease and life expectancy Annals of the New York Academy of Sciences 301:561.

Mesard L, Carmondy A, Mannarino E, Ruge D 1978 Survival after spinal cord trauma. Archives of Neurology 35:78.

MOELLER BA 1962 Incidence and distribution of blood pressure elevation in spinal cord injured patients. Proceedings of the Annual Clinical Spinal Cord Injuries Conference, pp. 47-54.

NyQuist RH, Bors E 1967 Mortality and survival in traumatic myelopathy during 29 years. Paraplegia 5:22.

RYDER RA 1979 Senate committee: amputation and cardiovascular disorders, Bulletin of Prosthetics Research, pp 21-29.

SaITo Y 1964 Clinicopathologic studies of chronic pyelonephritis by means of renal biopsies of the patients with injuries of the spinal cord. Tohuku fournal of Experimental Medicine 83:325.

TALBOT HS 1966 Renal disease and hypertension in paraplegics and quadriplegics. Medical Service Canada 22:570, 1966.

TARTOKOVSKI MI, CAREL RS, KAPLUNSKI MS 1983 Weight by height and age in Israeli adults Human Heridity 33:73-77.

TrIbe CR, SIlver JR 1963 Renal Failure in Paraplegics and Quadriplegics, Sir Issac Pitman \& Sons Ltd.

VAZIRI ND, GoRDON S, NIAKHTAR B 1982 Lipid abnormalities in chronic renal failure associated with spinal cord injury, Paraplegia 20:183. 